\title{
IMPLICACIONES DEL CONTROL NERVIOSO DEL FLUJO SANGUÍNEO COROIDEO EN LAS ENFERMEDADES OCULARES
}

\section{IMPLICATIONS OF NERVE CONTROL OF CHOROIDAL BLOOD FLOW IN OCULAR DISEASES}

\author{
DE HOZ MONTAÑANA R ${ }^{1}$, RAMÍREZ SEBASTIÁN AI ${ }^{1}$
}

Fisiológicamente, una de las principales funciones de la coroides es nutrir (aporte de $\mathrm{O}_{2}$ y glucosa) a las capas más externas de la retina (fundamentalmente a los fotorreceptores y al EPR). No obstante, la coroides parece estar perfundida en una proporción que excede de las necesidades nutritivas, sugiriéndose por tanto, un papel adicional para la alta tasa de flujo coroideo. Así se piensa que el flujo sanguíneo coroideo podría por un lado ayudar a mantener la regulación de la PIO y por otro tener una acción termorreguladora mediante los siguientes mecanismos: disipando el calor generado durante el proceso de fototransducción visual, previniendo el sobrecalentamiento de la retina externa durante la exposición a la luz brillante, y por último calentando las estructuras intraoculares que pueden enfriarse por la exposición con el medio externo en condiciones extremas.

En los últimos años se ha puesto de manifiesto que en la regulación de este flujo sanguíneo coroideo tiene un importante papel el control nervioso.

La neurorregulación del flujo uveal está gobernada por numerosos mecanismos. De forma directa, esta regulación se llevaría a cabo a través de la inervación perivascular, que permitiría un balance entre la vasoconstricción y vasodilatación necesarias para el mantenimiento del flujo sanguíneo; mientras que de forma indirecta se realizaría a través de las fibras paravasculares, tanto por medio de neurotransmisores clásicos, como por neuropéptidos liberados por las terminaciones simpáticas, parasimpáticas y sensitivas del estroma, y factores difusibles como el óxido nítrico.

En la coroides humana se ha observado que tanto las fibras perivasculares como las paravasculares se marcan con anticuerpos contra neuropéptidos propios del Sistema Simpático (Neuropéptido Y [NPY], Parasimpático (Péptido Intestinal Vasoactivo [VIP]) y Sensitivo (Sustancia P [SP] y Péptido Relacionado con el Gen de la Calcitonina [CGRP]) (1).

La estimulación simpática, causa una marcada vasoconstricción coroidea y una caída de la presión intraocular debido a una disminución en el volumen sanguíneo ocular (reducciones del flujo coroideo de hasta el 60\%). Esta respuesta fundamentalmente es llevada a cabo por la estimulación de receptores $\alpha$ adrenérgicos localizados en las células musculares lisas de los vasos. La inervación simpática, hace que la coroides esté bajo un tono vasoconstrictor, sugiriéndose que éste podría proteger a la retina y a la cabeza del nervio óptico de la hiperperfusión y rotura de las barreras oculares, que se pueden producir en ciertas circunstancias como por ejemplo la hipertensión arterial.

El papel de la inervación parasimpática está peor definido que el del sistema simpático. Sin embargo, se ha observado que la coroides responde a la estimulación colinérgica parasimpática (que le llega vía nervios ciliares cortos) mediante vasodilatación. Esta vasodilatación explicaría el incremento reflejo del flujo coroideo inducido por la luz.

Recientemente se ha postulado que también los nervios periféricos sensitivos juegan un importante papel en la regulación del flujo coroideo. Así, la SP, podría tener una función víscero-motora regulando el flujo coroideo durante la irritación ocular. Asimismo a la CGRP se le ha atribuido un papel vasodilatador como co-mediador colinérgico junto con la SP.

En vista de la importancia que el control nervioso ejerce sobre la regulación del flujo sanguíneo

\footnotetext{
1 Profesora Titular E.U. Instituto de Investigaciones Oftalmológicas Ramón Castroviejo. UCM.

E-mail:rdehoz@med.ucm.es / airamirez@med.ucm.es
} 
coroideo, parece lógico pensar que daños en la inervación coroidea podrían estar implicados en las alteraciones vasculares que se producen en algunas enfermedades oculares. Estudios experimentales han demostrado que la inervación simpática es crítica en la regulación de la vascularización coroidea, y que la pérdida crónica de la actividad simpática, puede contribuir a la proliferación vascular anómala que se observa en enfermedades como la degeneración macular asociada a la edad (DMAE) y la retinopatía diabética. Además, la pérdida de esta inervación puede causar edema en la retina, circunstancia que podría ser importante en enfermedades como la diabetes o la hipertensión, en las que el control autonómico está alterado.

El daño axonal en el Sistema Nervioso Simpático es un hecho muy notable de la neuropatía diabética. Además, se ha sugerido la existencia de una disfunción de los nervios simpáticos del ojo en pacientes diabéticos, postulándose que los episodios de hiperglucemia podrían determinar un aumento en el flujo coroideo y en la presión de los vasos de la coroides submacular, así como cambios en el epitelio pigmentario de la retina. De esta forma se exacerbaría la extravasación de fluido desde los vasos de la coroides submacular. El exceso de líquido intrarretiniano que origina el edema macular diabético procedería no sólo de los vasos de la retina sino también de la coroides, llegando a la retina a través de las lesiones del epitelio pigmentario cercano a la coriocapilar afectada.

Las fibras nerviosas coroideas son más numerosas en la coroides central que en la periférica. Este hecho es aún más notable en la región submacular, en la que los axones forman una delicada red, donde asimismo se encuentra el mayor porcentaje de células ganglionares coroideas $\mathrm{NPY}(+)$ y $\mathrm{TH}(+)$. $\mathrm{La}$ distribución mayoritaria de estas células en la región submacular, sugiere la posibilidad de que patologías vasculares de ciertas enfermedades oculares, como el edema macular diabético o la DMAE, estén relacionadas con la posible disfunción de estas células (2).

En la DMAE, las anomalías hemodinámicas se han descrito, tanto como agentes causales potenciales como parte del proceso patológico. Mediante flujometría Doppler con láser, se ha observado que el flujo sanguíneo coroideo disminuye con la edad, y es menor en los estadios no exudativos de la degeneración macular que en los controles; debiéndose este efecto a un descenso en el volumen del flujo sanguíneo (3). Se necesitarían más estudios longitudinales para determinar si estas alteraciones en el flujo sanguíneo coroideo participan de alguna manera en el desarrollo de la neovascularización coroidea, y si las medidas de flujo podrían identificar sujetos con DMAE con riesgo de desarrollar neovascularización coroidea. Igualmente, sería necesario un mejor conocimiento de la posible implicación de la inervación coroidea y especialmente de las neuronas submaculares, en esta enfermedad ocular.

Recientemente, se ha postulado que los nervios sensitivos podrían estar implicados en la regulación del flujo coroideo en distintos mecanismos inflamatorios que van a mediar la vasodilatación y extravasación plasmática. También se ha visto su papel en los procesos de mantenimiento y renovación vascular, con implicaciones substanciales en la función visual (4). Así, se ha sugerido, que cambios en el grosor coroideo jugarían un papel principal en la regulación de estado refractivo ocular, particularmente en la recuperación de la miopía (5).

Por tanto podemos considerar, que la inervación periférica, tanto sensitiva como simpática, tendría un amplio y significativo papel en la regulación de la arquitectura vascular coroidea. Más allá, dado la especial susceptibilidad al daño que presenta la inervación periférica, en gran variedad de condiciones, incluyendo: la edad, la hipertensión arterial, la hipertensión ocular y la diabetes; la disfunción de los nervios coroideos simpáticos y sensitivos podría intervenir en la etiología de las enfermedades oculares que aparecen asociadas a estas condiciones.

\section{BIBLIOGRAFÍA}

1. Triviño A, De Hoz R, Salazar JJ, Ramirez AI, Rojas B, Ramirez.JM. Distribution and organization of the nerve fiber and ganglion cells of the human choroid. Anat Embryol (Berl) 2002; 205: 417-430.

2. Triviño A, de Hoz R, Rojas B, Salazar JJ, Ramirez AI, Ramirez JM. NPY and TH innervation in human choroidal whole-mounts. Histol Histopathol 2005; 20: 393-402.

3. Grunwald JE, Hariprasad SM, DuPont J, Maguire MG, Fine SL, Brucker AJ, et al. Foveolar choroidal blood flow in age-related macular degeneration. Invest Ophthalmol Vis Sci 1998; 39: 385-390.

4. Steinle JJ, Smith PG. Sensory but not parasympathetic nerves are required for ocular vascular remodelling following chronic sympathectomy in rat. Auton Neurosci 2003; 109: 34-41.

5. Fitzgerald $M E$, Wildsoet $C F$, Reiner A. Temporal relationship of choroidal blood flow and thickness changes during recovery from form deprivation myopia in chicks. Exp Eye Res 2002; 74: 561-570. 